\title{
Geochemistry, mineralogy, solid-phase fractionation and oral bioaccessibility of lead in urban soils of Lisbon
}

\author{
${ }^{1 *}$ Reis A P, ${ }^{1}$ Patinha C, ${ }^{2}$ Wragg, J, ${ }^{1}$ Dias A C, ${ }^{2}$ Cave, M., ${ }^{3}$ Sousa, A.J., ${ }^{1}$ Costa, C., ${ }^{4}$ Cachada, A, ${ }^{1}$ Ferreira da Silva E, \\ ${ }^{1}$ Rocha, F., ${ }^{4}$ Duarte, A.
}

1.GEOBIOTEC, University of Aveiro, Campus de Santiago, 3810-193, Aveiro, Portugal

2.British Geological Survey, Nottingham, UK

3. CERENA, Technical Superior Institute, Av. Rovisco Pais, 1049-001, Lisbon, Portugal

4.CESAM, University of Aveiro, Campus de Santiago, 3810-193, Aveiro, Portugal

\section{Abstract}

An urban survey of Lisbon, the largest city in Portugal, was carried out to investigate its environmental burden, emphasizing metallic elements and their public health impacts. This paper examines the geochemistry of lead and its influence on human health data. A total of 51 soil samples were collected from urban recreational areas used by children to play outdoors. The semi-quantitative analysis of lead was carried out by inductively coupled plasma mass spectrometry after an acid digestion. X-ray diffraction was used to characterise the soil mineralogy. The solid phase distribution of lead in the urban soils was investigated on a sub-set of 7 soils, out of a total of 51 samples, using a non-specific sequential extraction method coupled with chemometric analysis. Oral bioaccessibility measurements were obtained using the Unified BARGE Method developed by the Bioaccessibility Research Group of Europe. The objectives of the study are: (i) investigation of lead solid-phase distribution; (ii) interpretation of lead oral bioaccessibility measurements; (iii) integration of metal geochemistry with human health data; (iv) understanding the influence of geochemistry and mineralogy on oral bioaccessibility. The results show that the bioaccessible fraction of $\mathrm{Pb}$ is lower when major metal fractions are associated to less soluble soil phases such as Fe-oxyhydroxides, and more elevated when the metal is in the highly soluble carbonate phase. However, there is some evidence that the proportion of carbonates in the soil environment is also a key control over the oral bioaccessibility of $\mathrm{Pb}$, irrespective of its solid phase fractionation.

Keywords: lead, soil mineralogy, solid phase distribution, oral bioaccessibility, human health 


\section{Introduction}

Urban soils are the 'recipients' of large amounts of environmental contaminants from a variety of sources including industrial wastes, vehicle emissions, coal burning waste and other activities. Some of these contaminants are widely recognized as human health burdens (Filippelli and Laidlaw 2010). Lead $(\mathrm{Pb})$ in particular is linked to severe cognitive and behavioural deficits (Lanphear et al. 2005; Chiodo et al. 2007). In areas where playgrounds, public gardens and parks are exposed to significant pollution levels, soil and dust from the ground may have toxic effects as a consequence of inhalation or ingestion by humans, particularly children, which poses major health hazards (Ljung et al. 2007; Ottesen 2008; Reis et al. 2013a). Soil ingestion is referred to in a number of case studies as a probable source of $\mathrm{Pb}$ exposure in children with elevated blood $\mathrm{Pb}$ levels in some areas. For instance in the USA, Johnson and Bretsch (2002) refer that the strong seasonal variation found in blood lead levels of young children suggests the importance of contaminated soils as an exposure source; Morrison et al. (2012) found a high degree of variability between soil $\mathrm{Pb}$ and blood lead levels but a good correlation between soil $\mathrm{Pb}$ and house interior $\mathrm{Pb}$ accumulation. In the solid phase, chemical elements occur as a complex mixture of compounds that includes discrete mineral phases, coprecipitated and sorbed species associated with soil minerals or organic matter, and dissolved species that may be complexed by a variety of organic and inorganic ligands. However, specific physico-chemical forms usually are not included in environmental studies on urban soils. Yet, not all forms of a given potentially harmful element (PHE) are solubilised in the gastrointestinal (GI) tract (Wragg et al. 2007; Reis et al. 2013b) and consequently absorbed to the same extent, which has implications in terms of health risk (Reis et al. 2013c). Therefore, the geochemistry of a PHE not only controls mobility and fate but also its oral bioaccessibility (fraction of the contaminant that is soluble in GI fluids) and hence, its oral bioavailability (fraction of the contaminant that is adsorbed in the GI tract). Palumbo-Roe et al. (2013) carried out bioaccessibility testing and mineralogical analysis on mine wastes from the Central Wales ore field, and found out that the bioaccessibility of $\mathrm{Pb}$ was controlled 
by the mineralogical composition of the wastes. In a study on urban soils, Wragg et al. (2007) use multiple regression analysis to predict the bioaccessibility of As and conclude that the dominant mechanism controlling As bioaccessibility is the release from the Fe oxides. A number of in vitro protocols were developed to assess the oral bioavailability of an element from its bioaccessibility (Ruby et al. 1999; Oomen et al. 2003). In Europe, such a protocol is currently under development by the BARGE (BioAccessibility Research Group Europe) group (Wragg et al. 2011). Determining the solid phase fractionation in the soil environment may be used as additional lines of evidence to support in vitro bioaccessibility testing. Sequential selective chemical extractions are a widely used method for characterizing the distribution of elements in the solid-phase (Li et al. 2001; Reis et al. 2012). However, a number of limitations are often associated to sequential chemical extraction schemes. Extensive reviews on the subject (Gleyzes et al. 2002; Filgueiras et al. 2002) illustrate the difficulty of finding a suitable method for all soil types and elements. Cave et al. (2004) propose a non-selective method coupled to chemometric analysis that is called Chemometric Identification of Substrates and Element Distributions (CISED). The interpretation of the CISED resulting data can be considered more challenging than that of data resulting from selective chemical extractions, since it requires a reasonable understanding on the geochemical and mineralogical characteristics of the solid matrices. However, several studies have been shown the CISED as a useful methodology for understanding the results provided by in vitro bioaccessibility tests (Palumbo-Roe and Klinck 2007; Wragg and Cave 2012; Cox et al. 2013). This paper presents and discusses mineralogical, geochemical (physico-chemical properties, pseudo-total concentrations, solid-phase distribution of $\mathrm{Pb}$ ) and health data (oral bioaccessibility of $\mathrm{Pb}$ in urban soils) obtained for seven soil samples that were subject to a multi-layering study. The objectives of the study are therefore to: (1) interpret lead oral bioaccessibility measurements obtained using the Unified BARGE Method (UBM); (2) investigate the solid phase distribution of lead using the CISED method, a nonspecific sequential extraction coupled to chemometric analysis, (3) investigate the influence of soil geochemistry/mineralogy on oral bioaccessibility, and (4) integrate environmental data with human health data. 
2. Materials and methods

2.1 The study area

Lisbon is the largest Portuguese city, has an area of $284 \mathrm{~km}^{2}$ and roughly half a million inhabitants. The smaller districts have higher population densities and are located near the Tagus River. Such districts outline the old part of the city and the majority of small public gardens and playgrounds are located in this area (Fig. 1).

The altitude of the city varies between the 5 meters along the Tagus River and 226 meters (above sea level) at the Monsanto forest park. This park occupies an area of approximately $10 \mathrm{~km}^{2}$ and is one of the largest urban parks in Europe. The relief of the city consists in a series of hills that are probably relics of ancient volcanic cones.

The land-use is mostly artificial land (90\% of housing, pavements, commercial land, etc) with minor uses as green-land (9\%) and agricultural land (1\%, mostly private household backyards, some of which are used to grow vegetables).

As in most cities over the world, the majority of collected soil samples correspond to a mixture of original mineral soils, transported soils, organic materials, pavement debris, building materials (bricks, paint, concrete, metal), urban waste, ash and slag. However, both the geochemistry and mineralogy of soils collected inside the Monsanto park are consistent with the underlying geology (Costa et al. 2012), which is the Volcanic Complex of Lisbon. The origin, time in situ, type and periodicity of maintenance of soils collected outside the Monsanto Park is unknown.

\subsection{Sampling and sample preparation}

Soil samples were collected from locations distributed across the city, depending on the location of urban recreational areas frequently used by children (Fig. 1). The sampling sites were selected in as regular 
pattern as possible across a study area of approximately $84 \mathrm{~km}^{2}$. In total, 51 samples were collected for the wider study of PHE in urban areas and seven soils from these were selected for this study of $\mathrm{Pb}$. At every location, a composite sample was collected which comprised of 3 samples collected from the upper $5 \mathrm{~cm}$ of the soil layer at the apexes of a triangle, at an approximate distance of $1 \mathrm{~m}$ from each other and mixed to minimize local heterogeneity. Duplicate samples were collected to estimate the sampling error and the lateral variability.

In the laboratory, soil samples were air dried in a fan assisted oven at $<40^{\circ} \mathrm{C}$ and sieved to provide the $<2$ $\mathrm{mm}$ and $<250 \mu \mathrm{m}$ size fractions. A representative amount of the $<2 \mathrm{~mm}$ fraction was grounded to a fine powder in an agate mill and used to determine physico-chemical properties of the soil. The $<250 \mu \mathrm{m}$ size fraction was used to obtain geochemical, mineralogical and health data.

\subsection{Analyses}

Soil $\mathrm{pH}$ was determined as $\mathrm{pH}_{(\mathrm{CaCl})}$ according to the ISO10390:1994 protocol. Soil organic matter (SOM) was determined by loss-on-ignition (LOI), at $430^{\circ} \mathrm{C}$ for about $16 \mathrm{~h}$ (Schumacher 2002). Elemental analysis of carbon, nitrogen, hydrogen and sulphur $(\mathrm{C}, \mathrm{N}, \mathrm{H}$, and $\mathrm{S})$ were determined by Element Analyzer. The soil organic carbon (OC) content was determined with $\mathrm{H}_{3} \mathrm{PO}_{4}(\mathrm{Skalar}$ Primac SCN) after the elimination of carbonates (Cachada et al. 2012). Cation exchange capacity (CEC) and the exchangeable cations were measured according to the ISO13536-1995 protocol. These soil properties were determined in the $<2 \mathrm{~mm}$ soil size fraction that it is the size fraction usually used in environmental studies.

Soil samples were digested using Aqua Regia at $95^{\circ} \mathrm{C}$ and the semi-quantitative analysis was carried out by ICP-MS at ACME Analytical Laboratories LTD., Canada. Precision of the results was determined through the analysis of laboratory replicates, sample duplicates, blanks and certified soil reference materials (Soil S1, Laboratory of Radiometric Analysis, Krakow, Poland; 7002, Analytika Co. Ltd, Czech Republic; NCSZC73004, China National Analysis Centre for iron and steel, China). Results of method 
blanks were always below detection limits. The results show values for precision (expressed as RSD \%) that are $<10 \%$, for all elements. The recoveries obtained for $\mathrm{Pb}$ in the certified soil reference materials vary between 81 and 107\%, within acceptable ranges.

The semi-quantitative mineralogical analysis of a sub-set of samples (seven soil samples in total) was carried out by X-ray diffraction, following the criteria of Schultz (1964), Thorez (1976), Galhano et al. (1999) and Oliveira et al. (2002). The clay fraction $(<2 \mu \mathrm{m})$ was obtained by sedimentation according to the Stoke's law. The identification of clay minerals was carried out using a Philips PW 3050 and X' Pert PW 3040/60 XRD equipment, through $\mathrm{Cu} \mathrm{K} \alpha$ radiation.

In order to determine exposure to $\mathrm{Pb}$ by the ingestion of urban soils, the bioaccessibility of $\mathrm{Pb}$ was determined by subjecting a sub-set of soil samples to the Unified BARGE Method (UBM), developed by the Bioaccessibility Research Group of Europe (BARGE). The UBM simulates the leaching of a solid matrix in the human GI tract (Wragg et al. 2011) and is a two stage in vitro simulation that represents residence times and physicochemical conditions associated with the gastric tract ( $\mathrm{G}$ phase) and the gastrointestinal tract (GI phase). The methodology has been validated against a swine model for arsenic (As), cadmium $(\mathrm{Cd})$ and lead $(\mathrm{Pb})$ in soils (Denys et al. 2012). In this study the concentrations used are those reported to the G-phase that is considered to provide a more conservative estimate of risk (Farmer et al. 2011). The bioaccessible extracts were analysed by ICP-MS at the University of Aveiro Laboratory and by ICP-AES at the British Geological Survey (BGS) laboratory. Duplicate samples, blanks, the bioaccessibility guidance material BGS 102 and the standard reference material NIST2711a were extracted with every batch of UBM bioaccessibility extractions for quality control. The blanks always returned results that were below the detection limit. The Pb recovery was 98\% for BGS 102 and 101\% for NIST2711a. Mean repeatability (expressed as RSD \%) was 5.6\% for the G phase.

The bioaccessible fraction $(B A F)$ of lead was calculated as follows:

$$
B A F=\frac{\text { highest } U B M \text { extracted concentration }}{\text { total concentration }} \times 100 \%
$$


To investigate the solid-phase distribution of $\mathrm{Pb}$ in each soil sample, a selected subset of seven samples from the total under investigation were subjected to the CISED method, which was developed by Cave et al. (2004). It is a non-selective sequential method that uses increasing concentrations $(0.01 \mathrm{M}, 0.05 \mathrm{M}, 0.1$ M, 0.5 M, $1 \mathrm{M}$ and $5 \mathrm{M}$ ) of Aqua Regia as extracting solutions, followed by ICP-AES analysis of major and trace elements of the extracts. A data processing algorithm is used to identify the number of physicochemical components extracted, their composition and the proportion of each in each extract.

\section{Results and discussion}

\subsection{Soil properties and bulk mineralogy}

Table 1 shows data for some soil properties measured in the sub-set of seven samples. From the studied samples, only soil of site 14 is classified as residual and in situ soil (Costa et al. 2012), formed by weathering of basalts (volcanic complex of Lisbon). The origin, time in situ, type and periodicity of maintenance of the other urban soils is unknown, which may explain the lack of correlation between textural features of the soil and the local geology (Costa et al. 2012).

Soils under study have neutral/near neutral $\mathrm{pH}$ values that range from 6.4-7.0 while the SOM is typical of garden soils (median value of $8.5 \%$ ). Under the near neutral $\mathrm{pH}$ of these soils $\mathrm{Pb}$ tends to be immobile as it is more soluble in non-calcareous soil below pH 5.2 (Salminen et al. 2005). The OC varies between 1.03 and $3.77 \%$, indicating that the soils have important amounts of inorganic carbon (probably as carbonates). The CEC of the soils is considerable, with values ranging from $5.27-48.26 \mathrm{cmol} / \mathrm{kg}$, which is probably due to the important amounts of SOM in the samples under study. The more abundant exchangeable cation is exchangeable-Ca (median values of $2.24 \mathrm{cmol} / \mathrm{kg}$ ) and the percentage of base saturation (\%BS) varies between 22.36 and $42.61 \%$, which are properties that give to the soils the capacity of neutralizing acidity in a short time period. The concentrations of TC, TN, TH, and TS (expressed as relative proportions) are in the ranges of $1.5-24.5 \%, 0.02-1.07 \%, 0.2-2.81 \%$ and $0.02-$ $0.11 \%$, respectively. 
Soils 14 and 47 have a bulk mineralogy dominated by carbonate minerals (mostly calcite) and in this study are labelled as calcareous soils. Soils 5, 8, 18, 33 and 39 have a predominance of silicate minerals (mostly quartz, K-feldspar and plagioclase) in variable proportions (Costa et al. 2012) and are labelled as siliceous soils. However, most soils have important amounts of carbonates, probably with an anthropogenic origin. As an example we can refer that pavement debris with a carbonate composition are visible in the bulk soil sample collected from site 39. Clay minerals such as kaolinite, smectite and illite were also identified (Costa et al. 2012). Illite is the predominant clay in soils 8, 33, 39 and 47 while sample 14 has important amounts of smectite. Since smectite has a high cation exchange capacity, the elevated CEC value determined for this soil is likely due to the presence of smectites (Costa et al. 2012).

\subsection{Pseudo-total and bioaccessible lead concentrations}

Oral bioaccessibility refers to the fraction of a contaminant that is released from soil into solution by GIfluids and represents the maximum amount of contaminant that is available for intestinal absorption (Ruby et al. 1999). In general, only a fraction of these bioaccessible contaminants can be absorbed by the intestinal epithelium and reaches the systemic circulation (bioavailable fraction). If the soluble fraction is the maximum concentration of contaminant that is available for absorption then bioaccessibility is a key factor limiting bioavailability and can be used as a conservative surrogate of bioavailability for risk assessment purposes.

Table 2 shows pseudo total and bioaccessible concentrations of $\mathrm{Pb}$ determined for the sub-set of seven samples. The table also presents $B A F$ values that were calculated using concentrations extracted in the $\mathrm{G}$ phase of the UBM method. The values are in the range 71 to $441 \mathrm{mg} \mathrm{kg}^{-1}$ for total $\mathrm{Pb}$ soil contents, in the range 47 to $261 \mathrm{mg} \mathrm{kg}^{-1}$ for bioaccessible concentrations and in the 45 to $92 \%$ range for $B A F$ estimates. The variability for the $B A F$ is probably due to the physico-chemical properties of the $\mathrm{Pb}$ species present in the solid-phase.

Figure 2 shows $\mathrm{XY}$ graphs for pseudo total concentrations, bioaccessible concentrations and $B A F$ of $\mathrm{Pb}$. The first plot (Fig 2a) shows that more elevated total concentrations correspond to more elevated 
bioaccessible concentrations of $\mathrm{Pb}$. However, no linear association was found between total concentrations and $B A F$ (Fig. 2b). Therefore, the bioaccessible fractions seem to be independent from the total $\mathrm{Pb}$ soil content, indicating that the total concentration is not a good indicator of the associated health risk.

\subsection{Solid-phase distribution of lead}

The solid-phase distribution study was carried out using the CISED method on a selected subset of seven samples from the 51 under investigation.

Pseudo total concentrations of $\mathrm{Pb}$ were used to calculate recoveries of the CISED extractions that are in the range $75-104 \%$. One duplicate sample extracted by different laboratories has recoveries of $100 \%$ (University of Aveiro) and 90\% (BGS). One duplicate sample extracted by the same laboratory (University of Aveiro) has recoveries of 98 and 100\%. The good recoveries in the duplicate samples suggests that lower recoveries are probably due to the presence of more resistant $\mathrm{Pb}$-containing mineral phases that are not dissolved by the CISED extracting solutions.

The CISED extracted components, their geochemical tentative assignment and plots showing the distribution of $\mathrm{Pb}$ in the identified components are presented in tables 3 to 5 .

Table 3 presents the results obtained for soil samples 8 and 39 that have $\mathrm{Pb}$ mainly associated to the SOM. Site 8 is a public park, the soil has a siliceous composition and an important SOM contents (Table 1). The chemometric model is composed by seven components (Table 3). Lead is clearly associated to the 6th ( $98 \%$ of the total $\mathrm{Pb}$ soil content) that is defined by the association Mg-Al-P. Phosphorus $(\mathrm{P})$ occurs in soils as both organic and inorganic forms, in variable proportions. The geochemical composition of the 6th component as defined by the mixture resolution modelling technique indicates a soil phase that is Sdepleted, suggesting an inorganic form for $\mathrm{P}$ (phosphates). Lead associated to a phosphate phase is not an odd result since several studies (Cao et al. 2009; Park et al. 2011) indicate that $\mathrm{Pb}$ in soils can be immobilised using phosphate compounds. Phosphate phases have the ability of sorbing a number of 
metals, $\mathrm{Pb}$ included. However, this soil has important contents of SOM and OC (Table 1). Therefore the 6th component is assigned to an organic soil phase (SOM). Although $98 \%$ of the total $\mathrm{Pb}$ soil content is extracted with this component, it represents only $4 \%$ of the total extracted solids and is considered to be a minor soil constituent. Sample39 was collected from a playground inside a public garden that has limestone pavements. The soil has a silicate composition but the amount of carbonate minerals reaches approximately $30 \%$ of the bulk mineralogical composition. Physical weathering of the limestone pavement is the probable source of carbonates in the soil. The chemometric model has nine components and most of the extracted $\mathrm{Pb}$ is associated to the $5^{\text {th }}$ (94\% of total $\mathrm{Pb}$ soil content), which is interpreted as an organic phase (SOM) and is extracted by medium to high acid concentrations (Table 3 ).

Approximately $3.5 \%$ of the total $\mathrm{Pb}$ concentration is in Ca-carbonates. The extracted $\mathrm{Pb}$-components represent $30 \%$ of the total extracted solids and are considered to be important soil constituents. Table 4 shows the results obtained for soil samples 5, 18 and 33 that have important metal fractions associated to carbonates. Sample 5 corresponds to a garden soil with a siliceous composition. The chemometric model has nine components (Table 4 ) and $\mathrm{Pb}$ is mainly associated to the $5^{\text {th }}(29 \%$ of the total $\mathrm{Pb}$ soil content) and $6^{\text {th }}(69 \%)$ (graph A). The $5^{\text {th }}$ component is geochemically assigned to an $\mathrm{Al}-\mathrm{Mg}$ rich carbonate phase while the $6^{\text {th }}$ is interpreted as clay minerals. The two soil constituents were solubilised by the medium acid concentrations (graph B). Minor amounts of $\mathrm{Pb}$ are in pore water soluble salts. The extracted $\mathrm{Pb}$-components represent $24 \%$ of the total extracted solids. Site 18 corresponds to a garden soil with a siliceous composition. The mixture resolution modelling technique identified seven components and $\mathrm{Pb}$ is mainly associated to the $4^{\text {th }}(93 \%$ of total $\mathrm{Pb}$ soil content $)$, which is defined by the association $\mathrm{Ca}-\mathrm{Al}$ and geochemically assigned to $\mathrm{Al}$-rich carbonates (Table 4). This $\mathrm{Pb}$-component is extracted by medium acid concentrations and represents $11 \%$ of the total extracted solids. A minor fraction of total $\mathrm{Pb}(5 \%)$ is probably absorbed at the surface of clay minerals ( $6^{\text {th }}$ component in table 4$)$. Sample 33 was collected from a small urban garden that is located within an area of intense car traffic and near an old petrol station. The chemometric model has nine components and $\mathrm{Pb}$ is mainly associated to the $5^{\text {th }}$ component $(91 \%$ of the total $\mathrm{Pb}$ soil content), which is defined by the association $\mathrm{Ca}-\mathrm{Mg}$ and 
interpreted as a carbonate phase. This Pb-component is extracted by medium acid concentrations and represents $16 \%$ of the total extracted solids. Minor fractions of the total $\mathrm{Pb}$ concentration are associated to Fe-Al oxyhydroxides (8\%). Although the carbonates seem to be important hosts of $\mathrm{Pb}$ in these three soils, the sample 5 has a different solid phase fractionation because the major metal fraction is associated to clays.

Table 5 presents the CISED results obtained for soil samples 14 and 47 that correspond to calcareous soils and have Pb mainly associated to Fe-oxyhydroxides. Sample 14 was classified by Costa et al. (2012) as a natural and in situ calcareous soil. The chemometric model has seven components (Table 5). Lead is mainly associated to the $6^{\text {th }}$ ( $88 \%$ of total $\mathrm{Pb}$ soil content) that is interpreted as Fe-oxyhydroxides and is extracted by medium to high acid concentrations. A small fraction of $\mathrm{Pb}(11 \%$ of total $\mathrm{Pb}$ soil content $)$ is associated to Ca-carbonates ( $4^{\text {th }}$ component). The main Pb-host (Fe-oxyhydroxides) represents $5 \%$ of the total extracted solids and it is considered to be a minor soil constituent. Site 47 is a small public garden located near the shipyard that is an important anthropogenic source of environmental $\mathrm{Pb}$. The soil is calcareous but there are no evidences that it corresponds to a residual soil. The modelling technique identifies nine components (Table 5) and $\mathrm{Pb}$ is mainly associated to the $4^{\text {th }}(91 \%)$ that is geochemically interpreted as amorphous Fe-oxides. This component is extracted by medium to high acid solutions. Minor metal fractions are also associated to crystalline Fe-oxides (5\%) and carbonates (2\%). In this sample the extracted $\mathrm{Pb}$-components represent $93 \%$ of the total extracted solids indicating that, in this soil, $\mathrm{Pb}$-phases are major soil constituents.

The overall interpretation of the data resulting from the solid phase distribution study shows that: (i) in calcareous soils (samples 14 and 47) $\mathrm{Pb}$ is mainly associated to Fe-oxyhydroxides while in siliceous soils carbonates and SOM are common host phases for the metal; (ii) extracted components assigned as Cacarbonates are normally $\mathrm{Pb}$-depleted but $\mathrm{Al}-\mathrm{Mg}$ rich carbonates commonly have $\mathrm{Pb}$; (iii) in the seven soils under study, $\mathrm{Pb}$ is usually extracted by medium to high acid solutions, which suggest that the host phases of $\mathrm{Pb}$ are not readily soluble in the soil environment. 


\subsection{Discussion of results}

Figure 3 shows plots with the solid-phase distribution of $\mathrm{Pb}$ for the sub-set of seven soil samples. Aiming for a better understanding on the relation between geochemical and health data, the bioaccessible concentration of $\mathrm{Pb}$ is also displayed in the graphs (dashed grey line).

Samples 8 and 39 are siliceous soils that have similar a solid phase fractionation for $\mathrm{Pb}$ (Table 3). More than $90 \%$ of the total $\mathrm{Pb}$ content is associated to $\mathrm{SOM}$ (Table 3) in both samples. However, according to figure 3 this soil phase is only partially soluble in the G fluids. In fact, the $B A F$ values are $66 \%$ for sample 8 and $59 \%$ for sample 39 . Organic complexation of metals in soil is not as well understood as inorganic complexation because of the difficultly of identifying the large number of organic ligands that may be present in the soil environment. Binding of metals to SOM involves a continuum of reactive sites, ranging from weak forces of attraction to formation of strong chemical bonds (US EPA 1992) and deriving different solubility. It is therefore reasonable to assume that different organic ligands in the soil environment can derive different bioaccessibility estimates. For example, Caboche et al. (2010) indicate a value of $35 \%$ as the mean bioaccessible fraction of $\mathrm{Pb}$ associated to $\mathrm{SOM}$, which is slightly lower that the values found in this study.

Lead in the siliceous soils 18 and 33 has a similar solid phase distribution (Table 4). Major metal fractions $(\cong 95 \%$ in soil 18 and $91 \%$ in soil 33 ) are associated to carbonates. These carbonate components seem to correspond to the bioaccessible forms of $\mathrm{Pb}$ (Fig. 3c and d) in the soil environment. This result is in good agreement with the estimated $B A F$ value of $92 \%$ (Table 2) obtained for sample 18. Other researchers have found similar results: Denys et al. (2012) refer that $\mathrm{Pb}$ carbonate forms and particularly cerussite are highly bioaccessible; Palumbo-Roe at al. (2013) indicate that higher bioaccessible $\mathrm{Pb}$ fractions are related to samples where cerussite occurred in the $\mathrm{Pb}$ mineral assemblage of mine wastes, irrespective of the presence other $\mathrm{Pb}$ mineral. For sample 33, the bad agreement between the bioaccessible fraction $(B A F=$ $69 \%$ ) and the solid-phase fractionation is due to the lower recovery obtained in the CISED extraction (Recovery $=75 \%$ ). In this study, lower recoveries are attributed to the presence of resistant mineral phases (see section 3.3) that are not dissolved by the high acid extracting solutions. Data presented in table 4 
indicate that a significant fraction of the total $\mathrm{Pb}$ content is in Fe-oxides, and the CISED high acid extracting solutions (Aqua Regia 5M) may not be able to dissolve more crystalline Fe-oxides.

Nevertheless, the results suggest that the $\mathrm{Pb}$ fraction in the carbonates phase is easily solubilised by the $\mathrm{G}$ fluids (Fig. 3d).

In soil sample 5 the major metal fraction seems to be associated to clays (Table 4). However, an important fraction (approximately 30\%) is in the carbonate phase. According to figure $3 \mathrm{~g}$, the proportion of $\mathrm{Pb}$ in bioaccessible forms corresponds mainly to the metal fraction that is in Al-Mg carbonates. However, the metal fraction associated to clays appears to be partly soluble in the G fluids.

Soil at sites 14 and 47 is calcareous and the solid-phase fractionation study shows that Fe-oxyhydroxides are the main hosts of $\mathrm{Pb}$ (Table 5). However, only a fraction of $\mathrm{Pb}$ in Fe-oxyhydroxides is bioaccessible (Fig. 3e, f), which is in good agreement with the low BAF values obtained (approximately $45 \%$ for both samples). Lower $B A F$ values are to be expected if most of the total $\mathrm{Pb}$ soil content occurs in less soluble phases such as Fe-oxyhydroxides. For example, Caboche et al. (2010) report a mean value of $10 \%$ for the fraction of $\mathrm{Pb}$ associated to amorphous Fe-oxides.

For the sub-set of seven samples under study, the bioaccessible fraction of $\mathrm{Pb}$ varies from about $90 \%$ when the metal is in the highly soluble carbonate phase to $45 \%$ when $\mathrm{Pb}$ is associated to the less soluble Fe-oxyhydroxides. This result indicates a strong control of the solid phase fractionation of $\mathrm{Pb}$ over its bioaccessibility. However, some studies indicate that the overall mineralogical composition of the soil also influences the bioaccessibility of PHEs. Pelfrêne et al. (2013) propose that higher Pb bioaccessibility in urban soils is due to high carbonate contents. In a previous study on the oral bioaccessibility of $\mathrm{Pb}$ in the urban soils of Lisbon that involved 19 soil samples, Reis et al. (2013c) refer a negative relation between the bioaccessibility of $\mathrm{Pb}$ and the carbonate content of the soil for samples with more than $20 \%$ of carbonate minerals in the bulk mineralogical composition.

To investigate a probable control of the soil mineralogy over the bioaccessibility of $\mathrm{Pb}$, the $B A F$ estimates are plotted against relative proportions of carbonates (Fig. 4) in the soil environment. An antipathetic behaviour is observable between the carbonate content of the soil and the $B A F$ of $\mathrm{Pb}$, with decreasing 
amounts of carbonates resulting in higher BAF values. It is likely that the dissolution of important amounts of carbonates by the acidic G-fluids can result in an increase of hydroxy carbonate anions available in solution, and that under such conditions $\mathrm{Pb}$ can form insoluble compounds with the anions. However, further investigation is necessary to confirm chemical/mineralogical transformations that may occur in the gastric environment. But if it is a fact that the calcareous soils have lower BAF estimates, it is also certain that in these soils $\mathrm{Pb}$ is associated to Fe-oxyhydroxides (Fig.4), which are less soluble soil phases. Moreover, if soils with higher BAF values correspond to silicate soils with lower proportions of carbonate minerals, these are also the soils in which the major hosts of $\mathrm{Pb}$ are carbonates that seem to be highly soluble in the G-fluids. In this sense, it is difficult to establish the role of soil carbonates in the bioaccessibility of $\mathrm{Pb}$. Nevertheless, it is worthwhile to discuss further the results obtained for soils 5 and 33. In soil 33 approximately $90 \%$ of $\mathrm{Pb}$ is in the highly soluble carbonate phase against only $30 \%$ in soil 5 that has also an important metal fraction associated to clays. But although $\mathrm{Pb}$ in soil 5 exists in less soluble soil phases, its bioaccessibility is more elevated (Table 2), which is an unexpected result. One possible explanation is that this sample has the lowest proportion of carbonate minerals (only $\approx 7 \%$ of the bulk mineralogical composition).

The results discussed in this study suggest that the solid fractionation of $\mathrm{Pb}$ is the key control over its oral bioaccessibility. However, such results do not discard the hypothesis that the carbonate content of the soil may be another key factor limiting the oral bioaccessibility of this PHE. If the proportion of carbonates modifies the oral bioaccessibility of $\mathrm{Pb}$, irrespective of its solid phase fractionation, this soil property may be a suitable predictor of bioaccessibility, and should be taken into consideration in human health risk assessment studies. But further studies are essential to fully understand this decisive link between the soil mineralogy and the bioaccessibility of $\mathrm{Pb}$.

\section{Conclusions}

This paper reports the results of a multi layered study carried out for a sub-set of seven soil samples, out of a total of 51 urban soils, and aims integrating metal geochemistry data with human health data. 
The solid-phase fractionation of $\mathrm{Pb}$ is variable among the studied samples but $\mathrm{Mg}$-Al rich carbonates seem to be common host phases of $\mathrm{Pb}$. Unexpectedly, the results indicate that Fe-oxyhydroxides are major hosts of $\mathrm{Pb}$ in carbonate soils. At site 47 , a small urban garden in the old city, the extracted $\mathrm{Pb}$ components represent $93 \%$ of the total extracted solids indicating that, in this soil, $\mathrm{Pb}$-containing soil phases are major soil constituents. An urban soil where the majority of the soil constituents contain $\mathrm{Pb}$ would certainly represent an increased environmental threat because the majority of its constituents have the ability of fixing environmental $\mathrm{Pb}$.

The joint interpretation of data resulting from CISED and UBM extractions indicates that $\mathrm{Pb}$ in carbonates is commonly bioaccessible but $\mathrm{Pb}$-containing soil phases such as $\mathrm{SOM}$ or Fe-oxyhydroxides are only partially soluble in the G fluids.

The $B A F$ of $\mathrm{Pb}$ is lower when major metal fractions are associated to Fe-oxyhydroxides, which are less soluble soil phases and more elevated when the metal is associated to the highly soluble carbonate phase. In this study, the joint interpretation of geochemical and human health data indicates that the solid phase fractionation is the key control over the oral bioaccessibility of $\mathrm{Pb}$, and shows that studies on the solid phase fractionation of a given PHE can be used as additional lines of evidence to support in vitro bioaccessibility testing.

However, samples that have lower $B A F$ values correspond to the calcareous soils. Moreover, samples with increasing proportions of carbonate minerals have decreasing $B A F$ values, suggesting some control of the soil mineralogical composition over the oral bioaccessibility of $\mathrm{Pb}$ in the gastric phase. Further investigation is necessary to achieve increase knowledge on the interactions between the solid matrices and the physiological fluids.

Multi layered studies that integrate geochemical, mineralogical and human health data carry more complex interpretations, are costly and cannot be carried out for large sets of samples. However, such studies would be powerful tools for human health risk assessment purposes as they: (i) are site-specific and therefore include a number of site-specificities in the risk assessment, (ii) provide increased 
knowledge on the bioaccessibility estimates, (iii) indicate suitable predictors of the oral bioaccessibility of the PHEs, and can be used to reduce the uncertainties associated to the prediction of the health risk.

\section{Acknowledgements}

The authors acknowledge the Foundation for Science and the Technology (FCT) for supporting the projects PTDC/CTE-GEX/68523/2006 and PEst-C/CTE/UI4035/2011. The authors also want to thank the reviewers for their helpful comments that significantly improved this paper.

\section{References}

Caboche, J., Denys, S., Feidt, C., Delalain, P., Tack, K., Rychen (2010). Modelling Pb bioaccessibility in soils contaminated by mining and smelting activities. Journal of Environmental Science and Health Part A, doi: $10.1080 / 10934529.2010 .493818$

Cachada, A., Pato, P., Rocha-Santos, T., Ferreira da Silva, E., Duarte, A. C. (2012). Levels, sources and potential human health risks of organic pollutants in urban soils. Science of the Total Environment, doi: 10.1016/j.scitotenv.2012.04.075

Cao, X., Wahbi, A., Mab, L., Li, B., Yang, Y. (2009). Immobilization of $\mathrm{Zn}, \mathrm{Cu}$, and $\mathrm{Pb}$ in contaminated soils using phosphate rock and phosphoric acid. Journal of Hazardous Materials, 164 (2-3), 555-564.

Cave, M. R., Milodowski, A. E., Friel, E. N. (2004). Evaluation of a method for identification of host physico-chemical phases for trace metals and measurement of their solid-phase partitioning in soil samples by nitric acid extraction and chemometric mixture resolution. Geochemistry: Exploration, Environment, Analysis, 4, 71-86

Chiodo, L. M., Covington, C., Sokol, R. J., Hannigan, J. H., Jannise, J., Ager, J., Greenwald, M., Delaney-Black, V. (2007). Blood lead levels and specific attention effects in young children. Neurotoxicology and Teratology, doi: 10.1016/j.ntt.2007.04.001

Costa, C., Reis, A. P., Ferreira da Silva, E., Rocha, F., Patinha, C., Dias, A. C., et al., (2012). Assessing the control exert by soil mineralogy in the fixation of potentially harmful elements in the urban soils of Lisbon, Portugal. Environmental Earth Sciences, doi: 10.1007/s12665-011-1362-8 
Cox, S. F., Chelliah, M. C. M., McKinley, J. M., Palmer, S., Ofterdinger, U., Young, M. E., Cave, M. R., Wragg, J., (2013). The importance of solid-phase distribution on the oral bioaccessibility of $\mathrm{Ni}$ and $\mathrm{Cr}$ in soils overlying Palaeogene basalt lavas, Northern Ireland. Environmental Geochemistry and Health, doi: 10.1007/s10653-013-9539-6

Denys, S., Caboche, J., Tack, K., Delalain, P., (2007). Bioaccessibility of lead in high carbonate soils. Journal of Environmental Science and Health, Part A: Toxic/Hazardous Substances and Environmental Engineering, doi: 10.1080/10934520701435569

Denys, S., Caboche, J., Tack, K., Rychen, G., Wragg, J., Cave, M., Jondreville, J., Feidt, C., (2012). In Vivo Validation of the Unified BARGE Method to Assess the Bioaccessibility of Arsenic, Antimony, Cadmium, and Lead in Soils. Environmental Sciences and Technology doi: 10.1021/es3006942

Farmer, J. G., Broadway, A., Cave, M. R., Wragg, J., Fordyce, F. M., Graham, M. C., Ngwenya, B. T., Bewley, R. J. F., (2011). A lead isotopic study of the human bioaccessibility of lead in urban soils from Glasgow, Scotland. Science of the Total Environment, doi: 10.1016/j.scitotenv.2011.08.061

Filgueiras, A. V., Lavilla, I., Bendicho, C., (2002). Chemical sequential extraction for metal partitioning in environmental solid samples. Journal of Environmental Monitoring, doi: 10.1039/b207574c

Filippelli, G. M., Laidlaw, M. A. S., (2010). The elephant in the playground: Confronting leadcontaminated soils as an important source of lead burdens to urban populations. Perspectives in Biology and Medicine, 53, 31-45.

Galhano, C., Rocha, F., Gomes, C., (1999). Geostatistical analysis of the influence of textural, mineralogical and geochemical parameters on the geotechnical behavior of the "Argilas de Aveiro" formation (Portugal). Clay Mineralogy, 34, 109-16.

Gleyzes, C., Tellier, S., Astruc, M., (2002). Fractionation studies of trace elements in contaminated soils and sediments: a review of sequential extraction procedures. Trends in Analytical Chemistry, 21 (6+7), $451-467$

Humphries, M. S., Kindness, A., Ellery, W. N., Hughes, J. C., (2010). Sediment geochemistry, mineral precipitation and clay neoformation on the Mkuze River floodplain, South Africa. Geoderma, 157: 15-26.

Johnson, D., Bretsch, J. K.., (2002). Soil lead and children's blood lead levels in Syracuse, NY, USA. Environmental Geochemistry and Health, 24, 375-385. 
Lanphear, B. P., Hornung, R., Khoury, J., Yolton, K., Baghurst, P., Bellinger, D. C., Canfield, R. L., Dietrich, K. N., Bornschein, R., Greene, T. et al. (2005). Low-Level Environmental Lead Exposure and Children's Intellectual Function: An International Pooled Analysis. Environmental Health Perspectives, doi: 10.1289/ehp.7688

Li, X., Poon, C., Liu, P. S., (2001). Heavy metal contamination of urban soils and street dusts in Hong Kong. Applied Geochemistry, 16, 1361-1368.

Ljung, K., Oomen, A., Duits, M., Selinus, O., Berglund, M., (2007). Bioaccessibility of metals in urban playground soils. Journal of Environmental Science and Health, Part A: Toxic/Hazardous Substances and Environmental Engineering, doi: 10.1080/10934520701435684

Morrison, D., Lin, Q., Wiehe, S., Liu, G., Rosenman, M., Fuller, T., Wang, J., Filippelli, G., (2012). Spatial relationships between lead sources and children's blood lead levels in the urban center of Indianapolis (USA). Environmental Geochemistry and Health, doi: 10.1007/s10653-012-9474-y

Oliveira, A., Rocha, F., Rodrigues, A., Jouanneau, J., Dias, A., Weber, O., Gomes, C., (2002). Clay minerals from the sedimentary cover from the Northwest Iberian shelf. Progress in Oceanography , 52, $233-47$

Oomen, A. G., Rompelberg, C. J. M., Bruil, M. A., Dobbe, C. J. G., Pereboom, D. P. K. H., Sips, A. J. A. M., (2003). Development of an In Vitro Digestion Model for Estimating the Bioaccessibility of Soil Contaminants. Archives of Environmental Contamination and Toxicology, doi: 10.1007/s00244-002$1278-0$

Ottesen, R. T., Alexander, J., Langedal, M., Haugland, T., Høygaard, E., (2008). Soil pollution in daycare centres and playgrounds in Norway: national action plan for mapping and remediation.

Environmental Geochemistry and Health, 30, 623-37.

Palumbo-Roe, B., Klinck, B., (2007). Bioaccessibility of arsenic in mine waste-contaminated soils: A case study from an abandoned arsenic mine in SW England (UK). Journal of Environmental Science and Health Part A, doi: 10.1080/10934520701435692

Palumbo-Roe, B., Wragg, J., Cave, M.R., Wagner, D. (2013). Effect of weathering product assemblages on $\mathrm{Pb}$ bioaccessibility in mine waste: implications for risk management. Environmental Science and Pollution Research, doi: 10.1007/s11356-013-1515-2 
Park, J. H., Bolan, N., Megharaj, M., Naidu, R., (2011). Comparative value of phosphate sources on the immobilization of lead, and leaching of lead and phosphorus in lead contaminated soils. Science of the Total Environment, 409, 853-860

Pelfrêne, A., Waterlot, C., Douay, F., (2013). Influence of land use on human bioaccessibility of metals in smelter-impacted soils. Environmental Pollution 178, 80-88.

Reis, A. P., Patinha, C., Ferreira da Silva, E., Sousa, A. J., (2012). Metal fractionation of cadmium, lead and arsenic of geogenic origin in topsoils from the Marrancos gold mineralisation, northern Portugal. Environmental Geochemistry and Health, doi: 10.1007/s10653-011-9433-z

Reis, A. P., Patinha, C., Noack, Y., Robert, S., Dias, A. C., Ferreira da Silva, E., (2013a). Assessing the health risk of aluminium, zinc and lead in outdoor dusts collected in recreational sites used by children at an industrial area in the western part of the Bassin Minier de Provence, France. Journal of African Earth Sciences, doi: 10.1016/j.jafrearsci.2013.08.001

Reis, A. P., Patinha, C., Noack, Y., Robert, S., Dias, A. C., (2013b). Assessing human exposure to aluminium, chromium and vanadium through ground-level dust ingestion in the Bassin Minier de Provence, France. Environmental Geochemistry and Health, doi: 10.1007/s10653-013-9564-5

Reis, A. P., Patinha, C., Wragg, J., Dias, A. C., Cave, M., Sousa, A. J., Batista, M. J., Prazeres, C., Costa, C., Ferreira da Silva, E., Rocha, F., (2013c). Urban geochemistry of lead in gardens, playgrounds and schoolyards of Lisbon, Portugal: Assessing exposure and risk to human health. Applied Geochemistry, doi:10.1016/j.apgeochem.2013.09.022

Rodriguez, R. R., Basta, N. T., Casteel, S. W., Pace, L.W., (1999). An in vitro gastrointestinal method to estimate bioavailable arsenic in contaminated soils and solid media. Environmental Sciences and Technology, 33, 642-49.

Ruby, M. V., Schoof, R., Brattin, W., Goldade, M., Post, G., Harnois, M., Mosby, D. E., Casteel, S. W., Berti, W., Carpenter, M., Edwards, D., Cragin, D., Chappell, W., (1999). Advances in evaluating the oral bioavailability of inorganics in soil for use in human health risk assessment. Environmental Sciences and Technology, doi: 10.1021/es990479z

Salminen, R., Batista, M. J., Demetriades, A., Lis, J., Tarvainen, T., (2005). Sampling. In: Geochemical Atlas of Europe. Part 1: Background Information, Methodology and Maps, (R. Salminen Ed,) Espoo, Finland, Geological Survey of Finland. 
Schumacher, B. A., (2002). Methods for the determination of Total Organic Carbon (TOC) in soils and sediments. EPA/600/R-02/069 (NTIS PB2003-100822), U.S. Environmental Protection Agency, Washington, DC.

Schultz, L. G., (1964). Quantitative interpretation of mineralogical composition from X-ray and chemical data for the Pierre Shale. U.S. Geol. Surv. Professional Papers. Washington, DC: U.S. Government Printing Office; 1964. 391-C: 1-31.

Spiteri, C., Regnier, P., Slomp, C. P., Charrette, M. A., (2006). pH-Dependent iron oxide precipitation in a subterranean estuary. Journal of Geochemical Exploration, 88:399-03.

Thorez, J., (1976). Practical identification of clay minerals: a handbook for teachers and students in clay mineralogy. Dison : Lelotte.

U.S. Environmental Protection Agency (EPA). Ground Water Issue. Behavior of Metals in Soils. Technology Innovation Office, Office of Solid Waste and Emergency Response, Washington, DC; EPA/540/S-92/018, 1992. online at http://www.epa.gov/superfund.

U.S. Environmental Protection Agency (EPA). Risk Assessment Guidance for Superfund Volume I: Human Health Evaluation Manual. National Center for Environmental Assessment, Washington, DC; EPA/540/R/99/005, 2004. Available from the National Technical Information Service, Springfield, VA, and online at http://www.epa.gov/ncea.

Wragg, J., Cave, M., Nathanail, P., (2007). A Study of the relationship between arsenic bioaccessibility and its solid-phase distribution in soils from Wellingborough, UK. Journal of Environmental Science and Health Part A, doi: 10.1080/10934520701436062

Wragg, J., Cave, M., Basta, N., Brandon, E., Casteel, S., Denys, S., et al. (2011). An inter-laboratory trial of the unified BARGE bioaccessibility method for arsenic, cadmium and lead in soil. Science of the Total Environment, 409: 4016-30.

Wragg, J., Cave, M., (2012). Assessment of a geochemical extraction procedure to determine the solid phase fractionation and bioaccessibility of potentially harmful elements in soils: A case study using the NIST 2710 reference soil. Analytica Chimica Acta, doi: 10.1016/j.aca.2012.02.008 
Zia, M. H., Codling, E. E., Scheckel, K. G., Chaney, R. L., (2011). In vitro and in vivo approaches for the measurement of oral bioavailability of lead $(\mathrm{Pb})$ in contaminated soils: A review. Environmental Pollution, 159: 2320-27. 


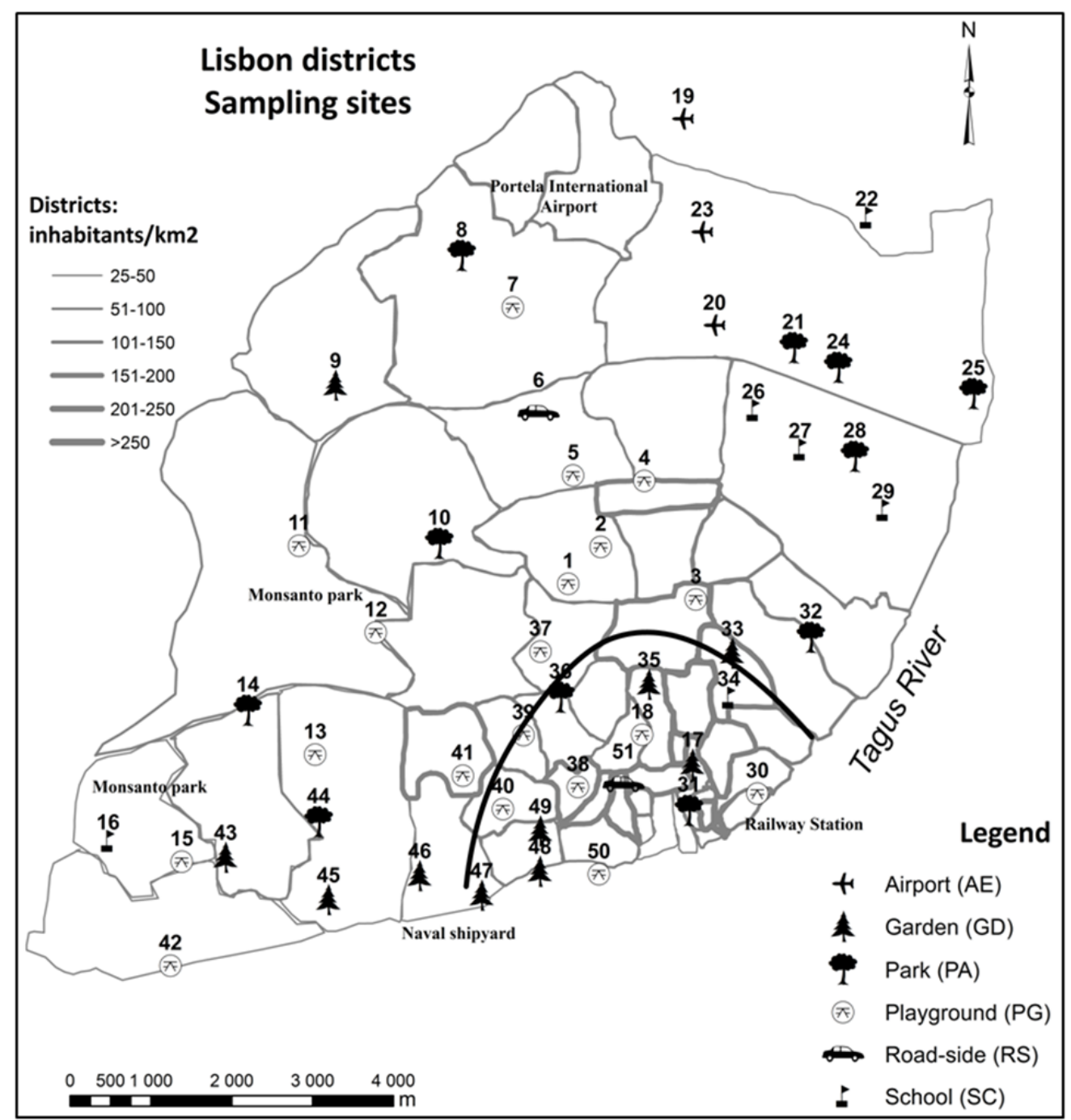

Fig1. Map of Lisbon showing the location of the 51 sampling sites and the type of recreational area at each site; grey lines delineate the 53 districts of the city and larger lines represent higher population density; the black line identifies the old city. 

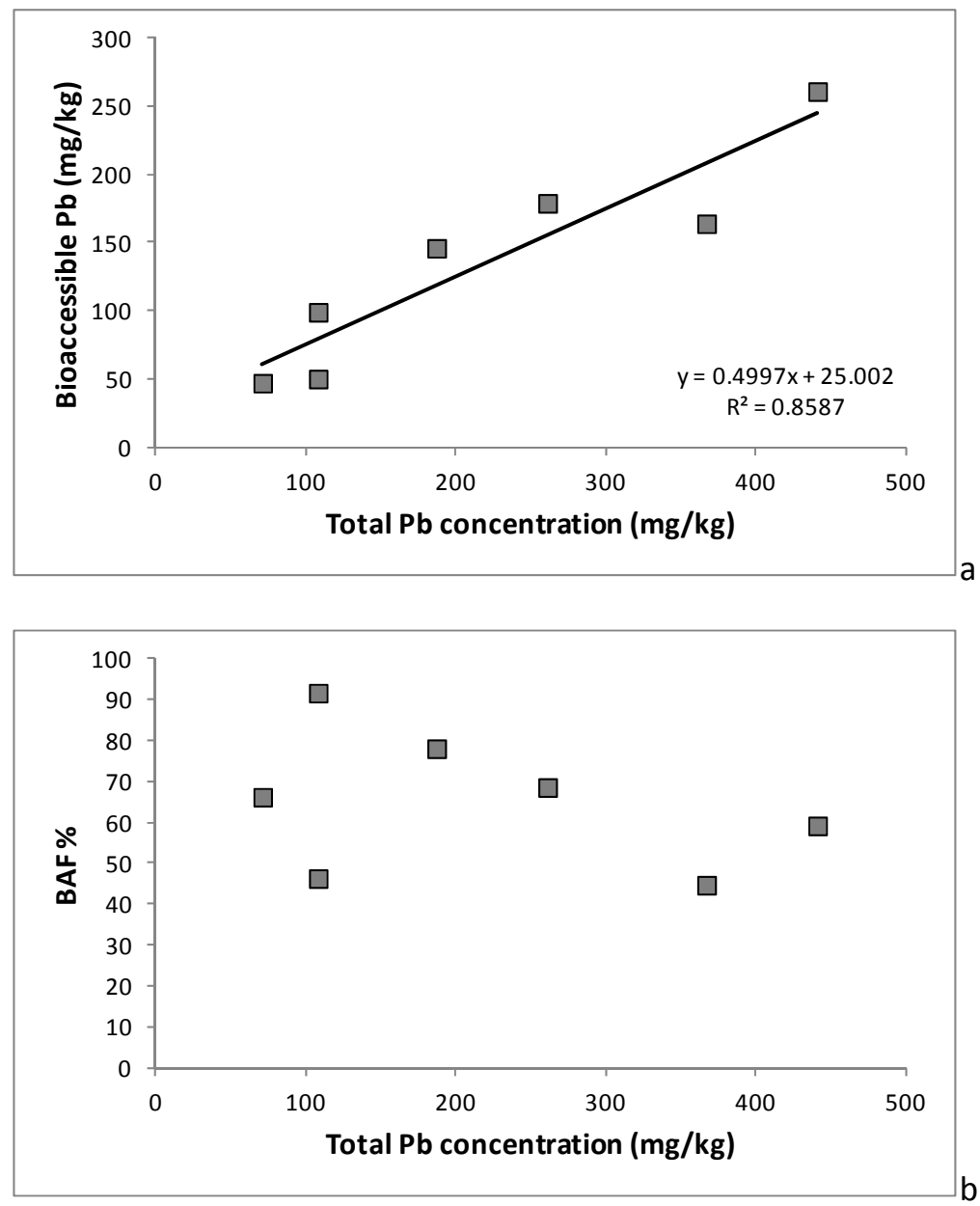

Fig2. XY graphs for pseudo total concentrations versus bioaccessible concentrations in the $\mathrm{G}$ phase (graph a) and total concentrations versus BAF (graph b). 


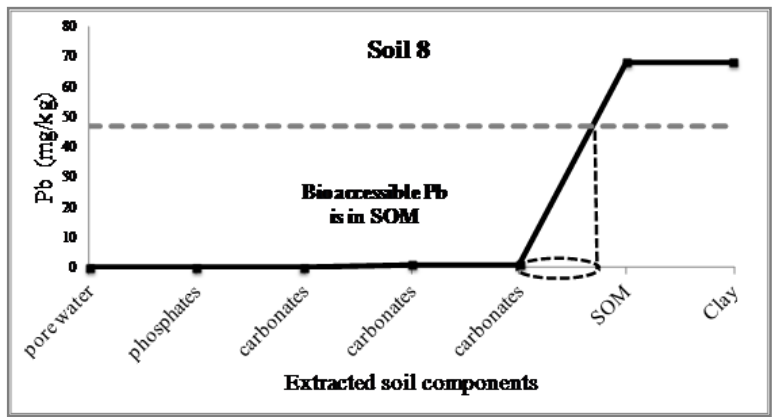

a)

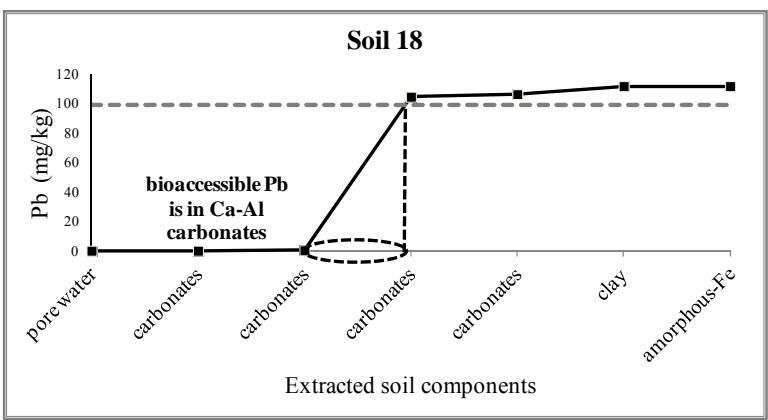

c)

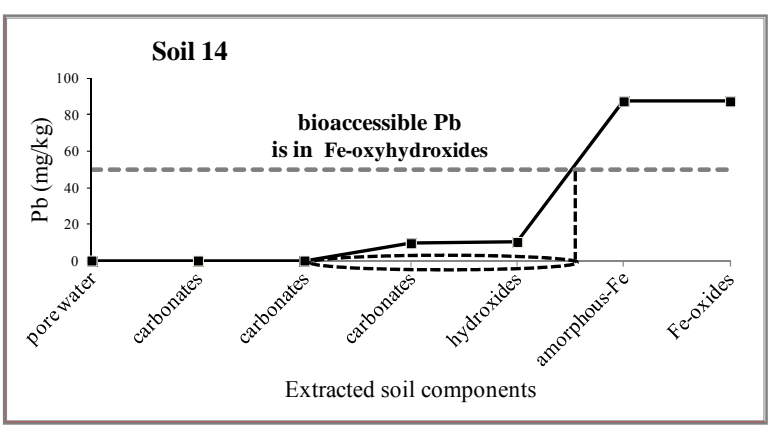

e)

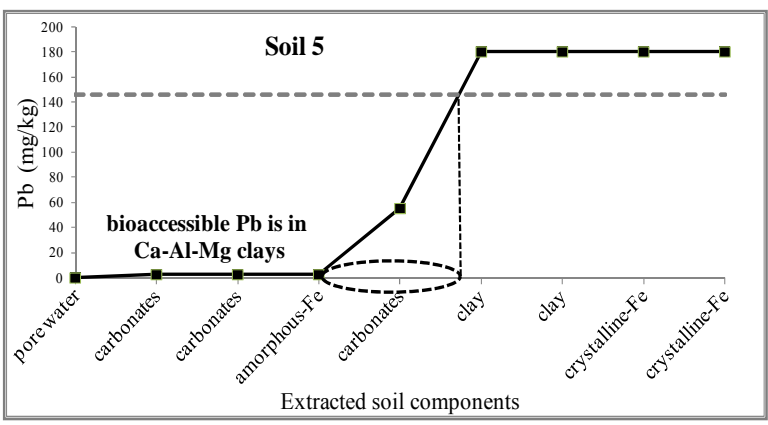

g)

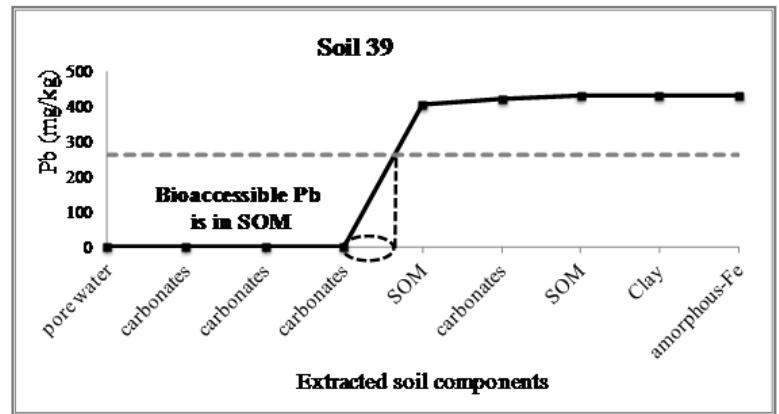

b)

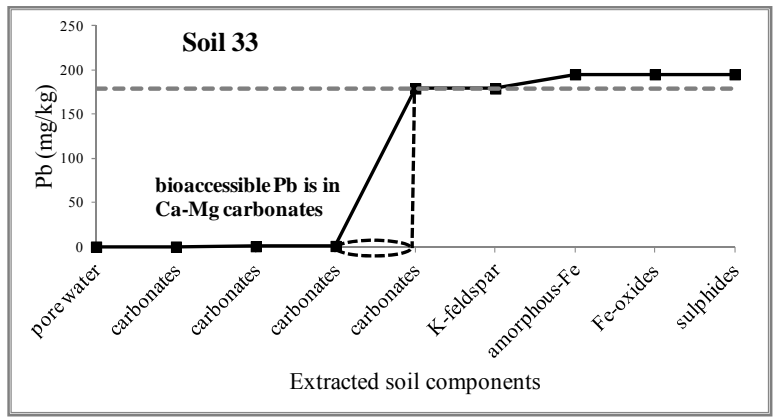

d)

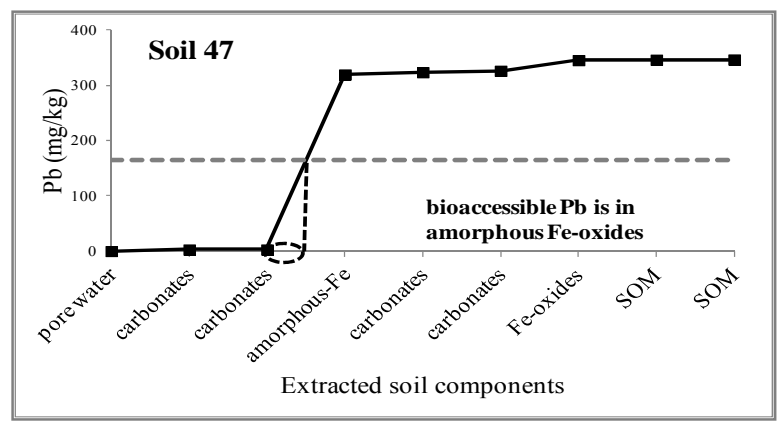

f)

Fig3. Cumulative linear plots showing CISEDextracted $\mathrm{Pb}$ concentrations in the identified soil components, for samples 8 (3a), 39 (3b), 18 (3c), 33 (3d), 14 (3e), 47 (3f) and 5 (3g); the dashed grey line represents the concentration of bioaccessible $\mathrm{Pb}$ determined in the $\mathrm{G}$ phase. 


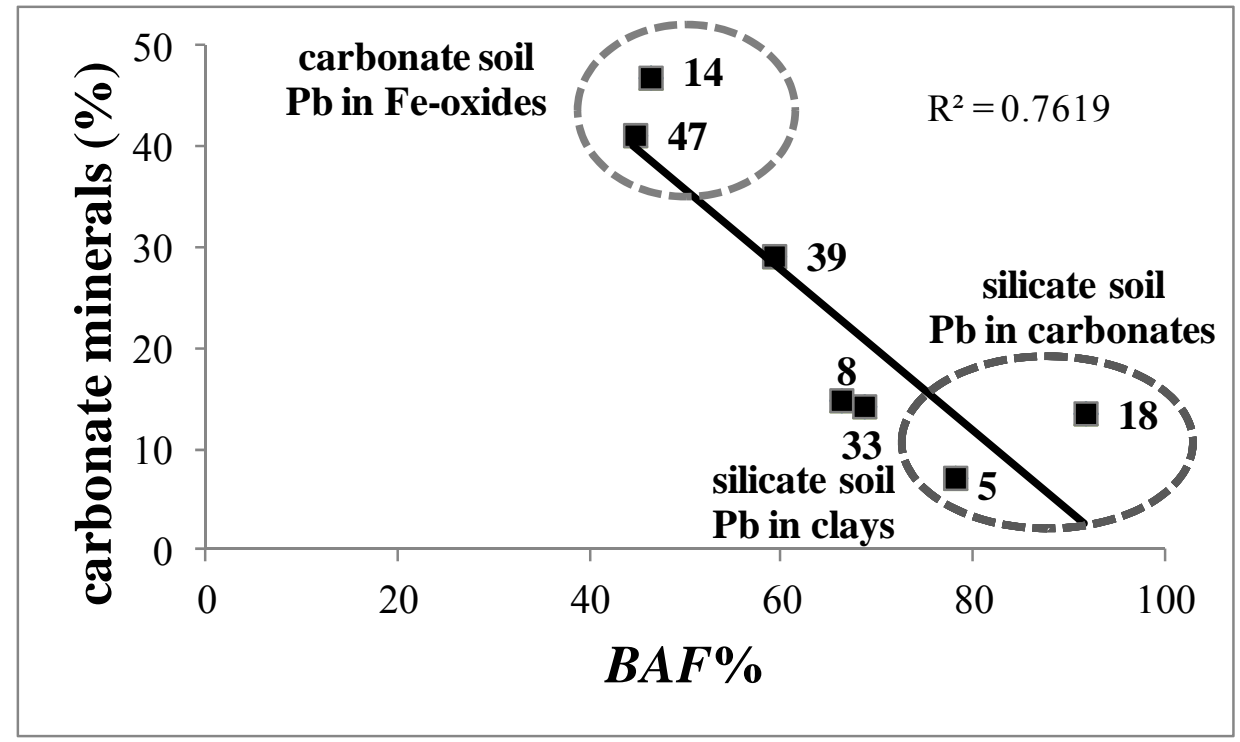

Fig4. $\mathrm{XY}$ graph displaying $B A F(\%)$ of $\mathrm{Pb}$ versus proportion of carbonate minerals in the bulk soil mineralogy (\%); data labels identify the soil phase that is the major host of $\mathrm{Pb}$ and the major mineralogical composition of the soil (silicates or carbonates). 
Table 1. Soil properties determined in the sub-set of seven samples selected for the multi-layering study.

\begin{tabular}{|c|c|c|c|c|c|c|c|c|c|c|c|c|c|}
\hline Sample & $\mathrm{pH}$ & $\mathrm{SOM}$ & $\mathrm{OC}$ & CEC & ExchNa & ExchK & ExchMg & ExchCa & $\% \mathrm{BS}$ & $\mathrm{TC}$ & $\mathrm{TN}$ & $\mathrm{TH}$ & $\mathrm{TS}$ \\
\hline 5 & 6.7 & 9.17 & 2.94 & 23.52 & 1.32 & 0.56 & 1.49 & 2.47 & 24.82 & 4.6 & 0.41 & 1.07 & 0.04 \\
\hline 8 & 6.6 & 12.20 & 3.17 & 26.74 & 0.32 & 1.11 & 2.01 & 2.54 & 22.36 & 10.9 & 0.67 & 1.46 & 0.03 \\
\hline 14 & 7.0 & 40.76 & 3.77 & 48.26 & 1.23 & 0.94 & 5.51 & 5.77 & 27.89 & 24.5 & 1.07 & 2.81 & 0.11 \\
\hline 18 & 7.0 & 1.81 & 1.22 & 5.27 & 0.57 & 1.32 & 1.01 & 1.33 & 35.51 & 3.1 & 0.26 & 0.62 & 0.02 \\
\hline 33 & 6.7 & 4.18 & 3.41 & 11.91 & 0.61 & 0.88 & 1.77 & 2.88 & 22.36 & 7.7 & 0.38 & 1.01 & 0.05 \\
\hline 39 & 6.4 & 7.65 & 1.03 & 21.05 & 0.37 & 1.67 & 1.76 & 2.22 & 23.45 & 9.1 & 0.46 & 0.98 & 0.04 \\
\hline 47 & 6.8 & 8.51 & 2.10 & 25.65 & 0.52 & 0.78 & 0.41 & 0.54 & 42.61 & 1.5 & 0.02 & 0.20 & 0.07 \\
\hline Median & 6.7 & 8.51 & 3.06 & 23.52 & 0.59 & 1.03 & 1.77 & 2.51 & 24.14 & 8.4 & 0.44 & 1.04 & 0.04 \\
\hline Mean & n.d. & 12.04 & 2.59 & 23.20 & 0.74 & 1.08 & 2.26 & 2.87 & 26.07 & 10.0 & 0.54 & 1.33 & 0.05 \\
\hline
\end{tabular}


Table 2. BAF, pseudo total and bioaccessible concentrations of $\mathrm{Pb}$ as determined in the sub-set of seven samples selected for the multi-layering study.

\begin{tabular}{c|ccc}
\hline Site & $\begin{array}{c}\text { Pb-total } \\
\mathrm{mg} \mathrm{kg}^{-1}\end{array}$ & $\begin{array}{c}\text { Pb-bio } \\
\mathrm{mg} \mathrm{kg}^{-1}\end{array}$ & $\begin{array}{c}\text { BAF } \\
\%\end{array}$ \\
\hline 5 & 187 & 146 & 78 \\
14 & 108 & 50 & 46 \\
18 & 108 & 99 & 92 \\
33 & 261 & 179 & 69 \\
39 & 441 & 261 & 59 \\
47 & 367 & 164 & 45 \\
Median & 187 & 146 & 66 \\
Mean & 220 & 135 & 65 \\
\hline
\end{tabular}


Table 3. Chemometric model, geochemical tentative assignment and $\mathrm{Pb}$ distribution in the extracted components for samples 8 and 39; graphs $\mathrm{A}$ and $\mathrm{C}$ show the distribution of $\mathrm{Pb}(\%)$ in the different components while graphs $\mathrm{B}$ and $\mathrm{D}$ show the profile of extracted $\mathrm{Pb}\left(\mathrm{mg} \mathrm{kg}^{-1}\right)$ along the extracting sequence; the black rectangles enclose $\mathrm{Pb}$-containing soil phases.

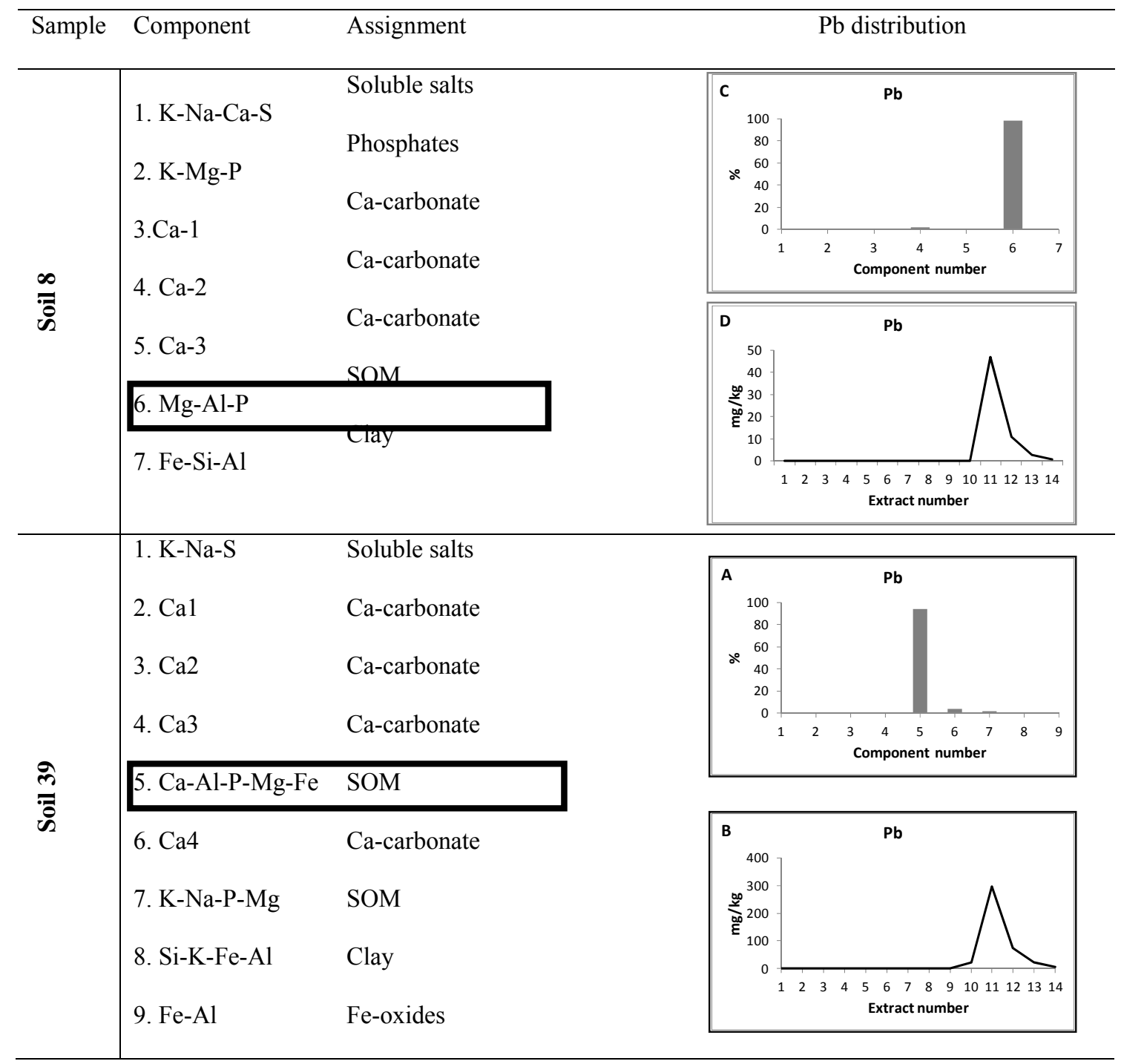


Table 4. Chemometric model, geochemical tentative assignment and $\mathrm{Pb}$ distribution in the extracted components for samples 5, 18 and 33; graphs $\mathrm{A}, \mathrm{C}$ and $\mathrm{E}$ show the distribution of $\mathrm{Pb}$ in the components while graphs $\mathrm{B}, \mathrm{D}$ and $\mathrm{F}$ show the profile of extracted $\mathrm{Pb}$ along the extracting sequence; the black rectangles enclose $\mathrm{Pb}$-containing soil phases.

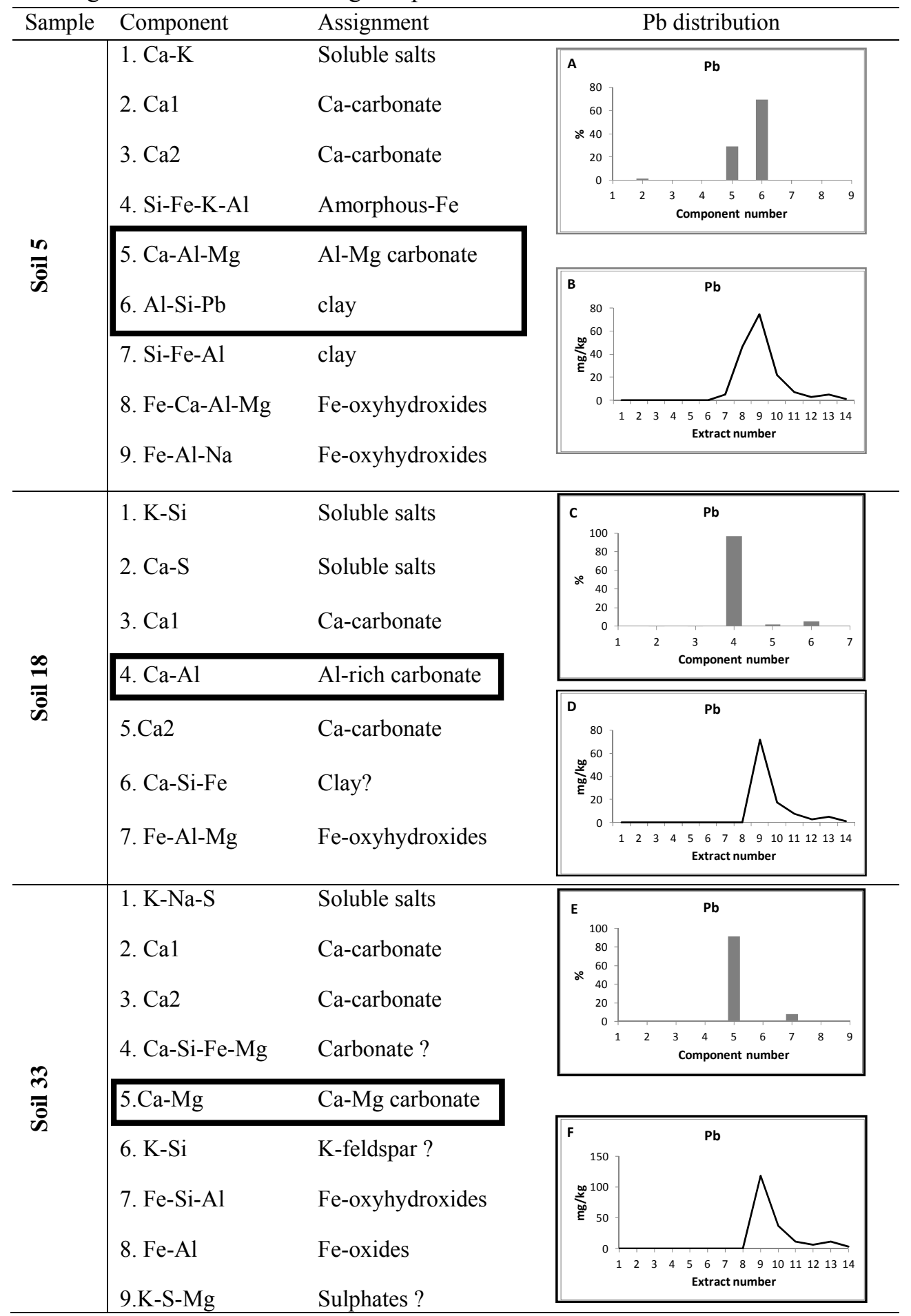


Table 5. Chemometric model, geochemical tentative assignment and $\mathrm{Pb}$ distribution in the extracted components for samples 14 and 47; graphs $\mathrm{A}$ and $\mathrm{C}$ show the distribution of $\mathrm{Pb}(\%)$ in the different components while graphs $\mathrm{B}$ and $\mathrm{D}$ show the profile of extracted $\mathrm{Pb}\left(\mathrm{mg} \mathrm{kg}^{-1}\right)$ along the extracting sequence; the black rectangles enclose $\mathrm{Pb}$ containing soil phases.

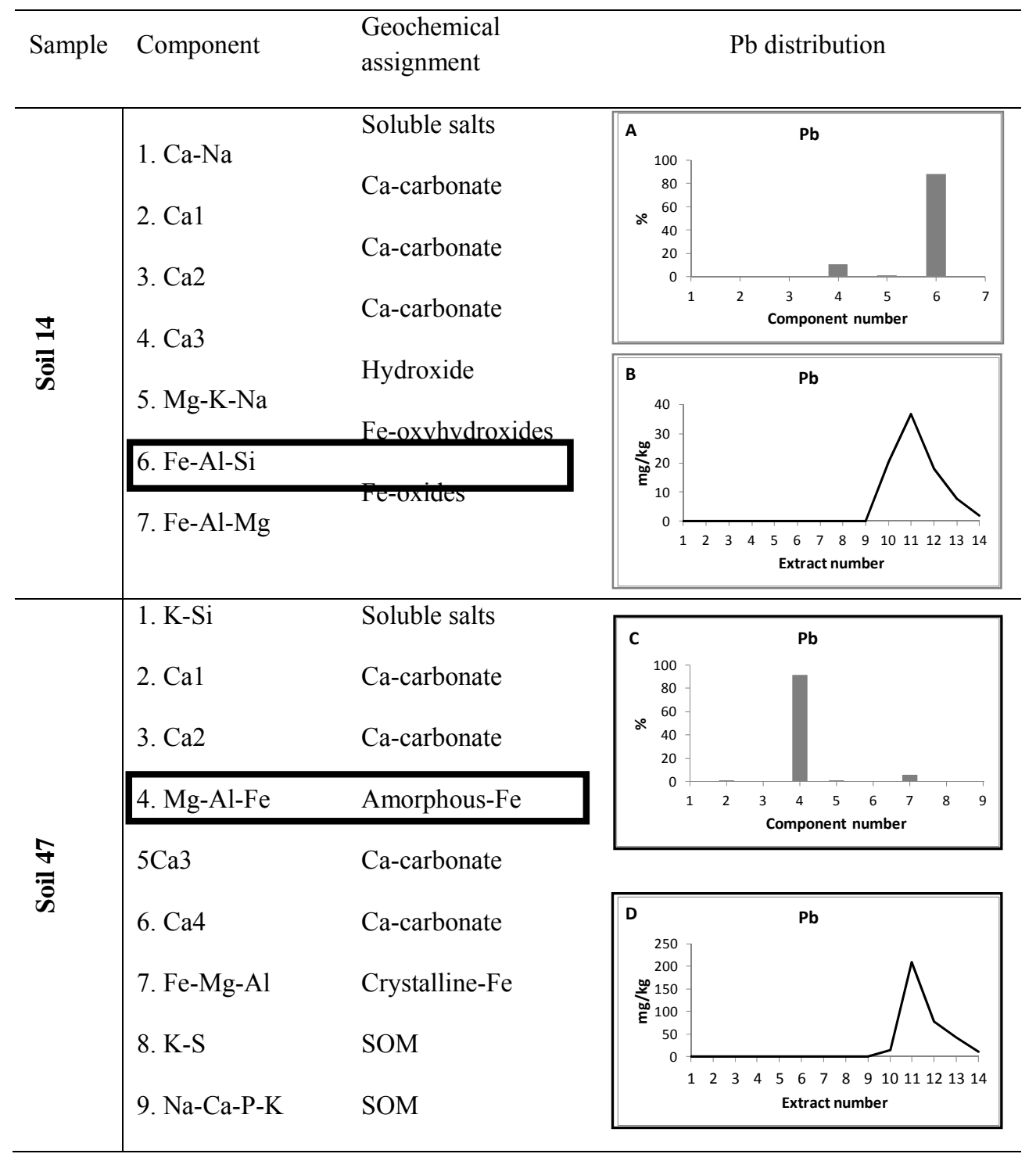

